\title{
«Organization and Behavior Pattern of an Individual within a Poly-Cultural Society. Issues Referring to Regulation of Different Cultural Values Relevancy Correlation in an Integral Modern Society, Ways of Interpersonal Relationship Poly-Cultural Development»
}

Lyazzat Ilimkhanova

PhD doctoral candidate, Independent Scientist - researcher, Email:lyazzat.ilimkhanova@gmail.com

Meruert Assylkhanova

Candidate of Psychological Sciences KazNPU after Abai. Email:phd2014.kz@gmail.com

Anar lkramova

Candidate of Pedagogical Scienses KazNPU after Abai. Email:phd2014.kz@gmail.com

Gulzhikhan Nurysheva Kazakh-British Technical University, head of Department of Humanities, doctor of philosophical Sciences, Professor.

Email: gulzhikhan-nurysheva@yandex.ru

Zhaksygul Sadykova

Candidate of Psychological Sciences KazNPU after Abai Email:phd2014.kz@gmail.com

Makhabbat Sadykova

Candidate of Pedagogical Sciences KazNPU after Abai.

Email:phd2014.kz@gmail.com

Sulu Issabayeva

Candidate of Pedagogical Sciences KazNPU after Abai Email:phd2014.kz@gmail.com

Gulzada Sipirindiyeva

Master of Pedagogical Sciences, KazNPU after Abai Email:phd2014.kz@gmail.com

Doi:10.5901/mjss.2014.v5n20p2777

Abstract

Vector oriented at a certain stability level and set up by state, has a direct impact over the social and cultural environment development and changes within this environment. In this respect, some of the most significant issues arisen in the context of globalization in poly-cultural Russia became difficulties of implementing the Western states programs on interpersonal relationship regulation within a poly-cultural society. In this respect a non-standard approach should be adopted and specificity of dealing with more than one hundred diverse cultures and ethnic groups should be considered. This requires a full-scale research of any possible ways to settle the poly-cultural society organization issue, this society being based on tolerance and mutual respect principles. The results of investigations performed obviously show that a complex solution is needed to create new patterns of communication and sustainable cooperation between different cultures, taking into account the multitude of distinct features and ways of settlement.

Keywords: organization, behavior pattern, educational approach, personal culture, political behavior, ethnic affiliation, ethnos, individual, social environment. 


\section{Introduction}

The issue of the individual tolerant behavior building and organization within a poly-cultural society is topical all over the world. Mainly, this refers to the ethnical identity significance growth in the context of political, social and economic aspects internationalization. Increase of reversion to their origins among the representatives of ethnic minority and large groups had a significant impact over the reconsideration of tasks assigned to most important individual socialization institutions.

The multi-ethnic instability represents one of the most important factors influencing the individual behavior patterns and norms within an environment. An accent on this instability is put by the inter-ethnic tension. At present this issue is topical in all Eastern, Western, Northern and Southern regions and it drew a certain response, this resulting in issues directed to new solutions checking and implementation at the educational institutions level. The migration process growth made specialists pass to the experience of countries historically subject to a high migration level, such as FRG, Canada, USA. Many actual special programs on education and behavior norms have been worked out on the model of these states namely.

\section{Research \& Results}

At present, development of programs on the individual behavior setting up is the result of topical issues and their effective settlement methods adjustment. The "proletarian internationalism" long-lasting period had the expected reverse impact; that is why the public conscience lever moved to the opposite - the patriotic idea re-emerged, this fact being repeatedly mentioned by both foreign and national authors. The research performed showed that, on the ex-Soviet Union territory, solidarity with their ethnic community and culture are some of the not so many attractive values for modern representatives of different generations.

The issue of the individual certain behavior norms organization is made even more complex for several reasons. Particularly, the Russian Federation consists of 89 territorial subjects including not less than one hundred and twenty ethnic groups. Even supposing the poly-cultural community provides a favorable life situation, this community development exerts a certain influence; that is why the inter-group tension remains an essential and intractable problem. The tension itself has a multitude of expression patterns. In this regard, even the lack of conflict actions cannot guarantee the non-existence of a private type conflict emergence, based on the long-brewing enmity, where the constrained communication of certain people with the culture representativesbecomes the pretext and reason for a future conflict.

The ethnic conflict issue may be considered in different aspects. The research shall start from the less pronounced levels at initial stages - educational institutions, namely schools. The students of different nationalities try to reduce the probability of the inter-ethnic contact rise. Students representing different cultures are rarely friends. Further on, in most cases, the indifference towards other ethnic groups evolves into aggression, based on the ethnic factor in its artificially exaggerated expression. It becomes significant for the identity mark accentuation or differentiation between individuals. According to the survey results performed byEducation Sociology Centre RAE, there is a conclusion attesting a high conflict level among Russian teen-agers, these conflicts having an ethnic basis. Evaluation results showed that one in four of the interviewed teen-agers participated to a varying degree in such conflict situations.Non-tolerant behavior expressed overtly is characteristic of almost 10\% of pre-school children (Gluhova, Muterperel, Sobkin, 2003).

The tension increase in the inter-ethnic relationship area is a result of the economic and political instability, armed conflicts in the former Soviet Union, these conflicts contributing to the migration flows increase. In this regard, it is necessary to take certain measures aimed at regulating the society poly-cultural education issue - migrators' children education and training. It is necessary to make sure there is a tolerant attitude towards them, this becoming the main task of the new individual behavior pattern.

Even a brief review of the circumstances mentioned above becomes the basis for new approaches evolvement, these approaches being based on the individual political ethics development allowing evolvement of an effective model referring to thebehavior social norms.

Poly-cultural society emergence: education

The advantageof multi-culturalism became one of the main incentives for the poly-cultural education concept evolvement at the beginning of the 80s of the XX-th century. This trend has developed in many countries of the world; it was based on the assertion that no culture existent in the human history may be viewed as an uninvited guest, and its bearer cannot be regarded as a cultural impostor (Perotti, 1995, p.36).

With the course of time, the behavior models and education conception was subject to change, and today the principles of poly-cultural education adherent to the multi-ethnic society are not put on a sound basis, as, according to 
many authors, the support ideology of this trend yields from wrong assertions:

- The poly-cultural society representation, as being the unique "melting pot" is wrong. People cannot give up on the tendency to preserve their basic culture; they can only indirectly mix a certain affiliation to several cultural values;

- It is wrong to regard the poly-cultural society as being a "mosaic structure" consisting of different cultures. Any culture development is based on the multicultural interdependence;

- Research of the poly-cultural society cannot be based on the "majority-minority" opposition principle, as a result of many ethnic minorities coexistence within one social environment, particularly, their cultures interaction with one another.

Thus, the "poly-cultural society" interpretation is not based on the principle of people coexistence forms adherent to strictly one cultural or ethnic group. It is based on the fact that a lot of people are, to a certain extent, members of several societies and bearers of two or more cultures which are in a continuous dynamics and intermix. The individual behavior patterns setting up within a poly-cultural society is a complex procedure, as this society is characterized by social diversity and this diversity is basically changeable.

At present, the socialization success directly depends on the choice opportunity; that is the individual may evaluate by himself the necessity and reason for change in identity, cultural values and ethnic preferences. Tolerant attitude towards "the others" is possible only the context of a certain freedom from self-expression limits and diverse behavior patterns adoption in various cultural environments. Organization of the individual behavior norms within a poly-cultural society shall be based on a certain freedom of choice balance and collective identity promotion tasks. (Stefanenko, Belinskaya, 2000). The answers of respondents to the question "Has the Kazakh nation been set up in Kazakhstan?" have generally been affirmative. Thus, about one fifth of experts maintain a more optimistic position, asserting that the Kazakh nation has already been set up. Another part of experts judges by the fact that the Kazakh nation phenomenon is a spiritual entity rather than a real, social and political one. They believe that the Kazakh nation exists at the mindset and culture level of Kazakhstan nations. The point at issue is that the co-existent ethnic groups and communities have accumulated common spiritual values and traditions. The difference in these positions is certainly significant; however, both of these trends represent a support to the thesis of the Kazakh nation phenomenon existence. Thus, the answers of more than one half of experts may be considered as affirmative.

About one fourth of experts maintain an uncertain position: they believe that the Kazakh nation phenomenon may arise in the context of a purposeful policy promoted by the state. The persons inclined to a negative opinion on the Kazakh nation existence issue account for less than $19,6 \%$ in total. About $13,2 \%$ of them believe that there is no such a phenomenon in the Kazakh reality, this being a convenient political lever only. This skeptical attitude may be based on either a negative personal experience or theoretical models. The remaining $6,4 \%$ of experts showing a negative attitude believe that this phenomenon may not exist within such a multi-ethnic society as Kazakhstan is.

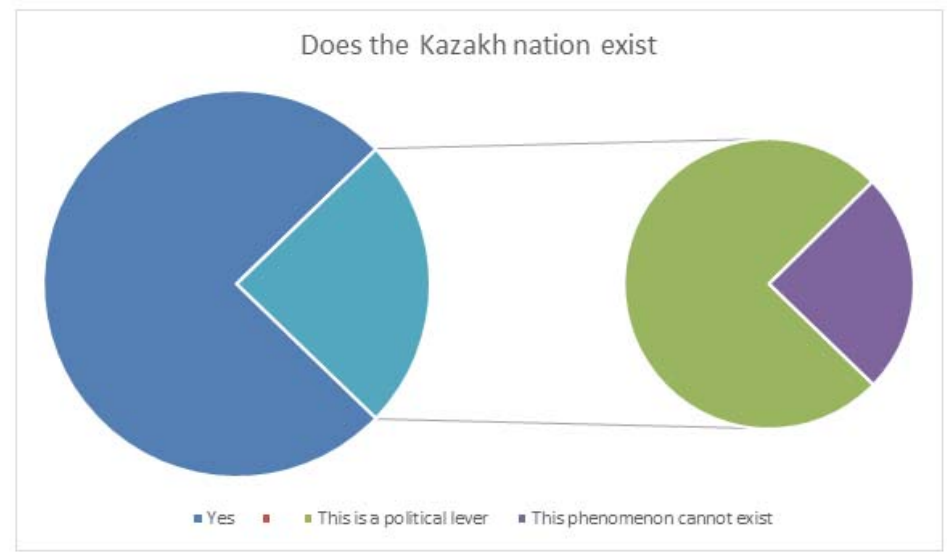

Another issue arising contrary opinions -does the ethnical image setting up require adoption of certain documents (laws, conceptions, codes, etc.,) or this process shall be included in the "people's art" natural regime. In experts' opinion, special documents are necessary to reflect the principles of the state national policy. 
A positive ethnical image depends on the opinion of the ethnical groups themselves on the inter-ethnic relationship within the country, its changes, influencing factors, etc.

Relations among the ethnic groups are nowadays appreciated as being balanced and friendly. This opinion is supported by the Uzbeks $(93,3 \%)$, the Koreans $(90 \%)$, the Kazakhs $(89,3 \%)$, and the Ukrainians $(84,9 \%)$. There have been many respondents among the Germans to emphasize the neutrality of relations. Referring to the Russians, one quarter of respondents consider that the inter-ethnic relations within the country are friendly, one fifth of them believe that these relations are neutral and only about $4 \%$ - consider them to be strained and conflictive. This opinion is mostly supported by the Uighurs in comparison with other ethnic groups.

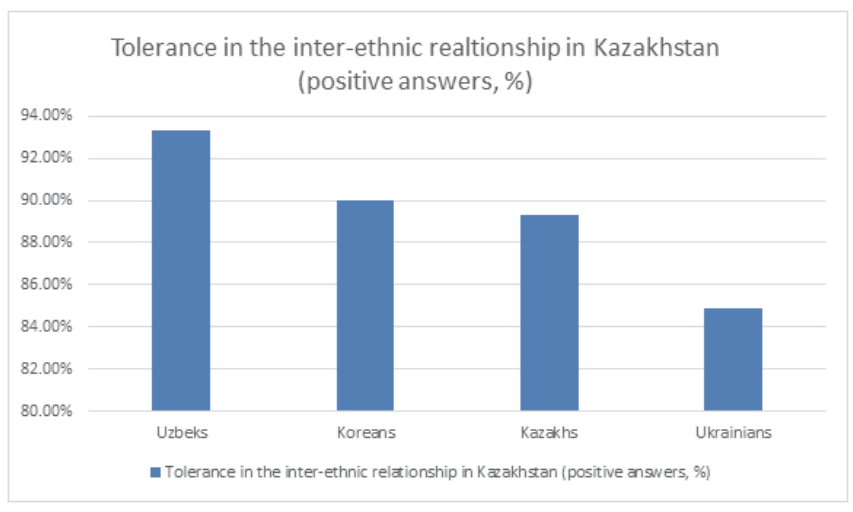

One of the indicators of the inter-ethnic distance is attitude to cross marriages. In this respect, the Koreans from Kazakhstan show the most tolerant attitude: $50 \%$ of them are positive, $27,8 \%$ are neutral and only $5,6 \%$ are negative in this respect. The positive attitude prevails within the German, Ukrainian and Russian respondents. In contrast, the Kazakhs, Uighurs and Uzbeks maintain a critical position on this issue.

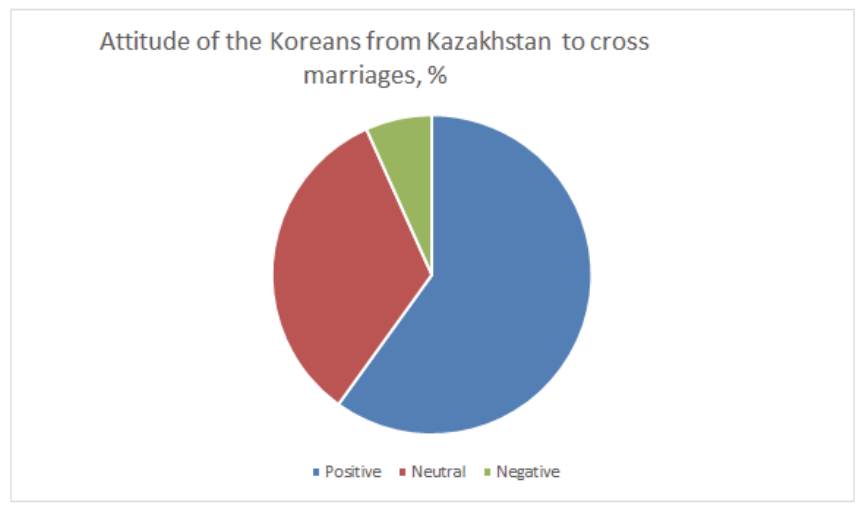

At present, the detailed analysis of programs on education and individual behavior norms in a poly-cultural society provides solutions for the main problems:

- Personal enhancement- assumes an individual approach;

- Cultural and ethnic competence development - contributes to improvement of the information awareness on peculiarities of the ethnic groups culture and history (both own and adherent to "others");

- Setting up of the intercultural competency basis - in this context, not only the positive attitude to other ethnic and cultural groups existence is important, but also the ability to contact these groups representatives, that is the ability to understand and interact;

- Development of the society representatives' awareness of the inevitable interconnection and mutual enrichment of the contemporary world cultures, as well as of the interactive processes. 
Psychological research of the behavior patterns showed that positive result in the poly-cultural society development area may be achieved by means of setting up over-ethnic groups, as well as overviewing in details the crossover values similarities; reducing the disregard of other groups significance; organizing intergroup contacts in the context of a favorable political and economic environment; enhancing the real significance and influence of humanitarian values; becoming aware and more informed on behavior and values discrepancies aimed at reducing the possibility of conflict situations rise in the process of different groups communication within a poly-cultural society; generalizing and analyzing the advantages of communication and interaction experience of other groups' representatives.

Patterns and programs on behavior organization within a poly-cultural society shall be worked out not only for educational institutions, characterized by a continuous interaction among different cultures' representatives, but also within the cultural and homogeneous environment. Thus, for example, in the schools of Israel, children from their infanthood study the disciplines of "school integration" and "intercultural training". The second discipline is not aimed at achieving the community representatives' intercultural integration; instead, it is directed to reducing the ethnocentrism significance and making children aware of the differences and other peculiarities defining the development of tolerance to different cultures representatives (Amir, Shachar, 1996).

These programs are effective and have positive results in the intercultural interaction area, being based on the single functional pattern of individuals' organized and conscious informing by means of the corresponding methods and processes (Kopteltsova, Rot, 2001, p.16).

The Netherlands should be considered an example of the best organization and the corresponding behavior patterns adoption, characterized by respect and a kind towards any nationality representatives. Particularly, starting from 1990, a program called "We All Live Here" is in force. It consists of 30 courses included in the curriculum. The efficiency of courses is based on lack of rigidity in regulation. Every course begins with a presentation carried out by the teacher, this presentation being based on a concrete story, of which the protagonist is the peer of trainees. The students have to familiarize themselves with the story and develop its content based on their personal experience. As a result, every situation is understandable and an accent is put on either the ethnic or cultural moments.

In other countries, for example USA, the issue of behavior patterns emergence within the poly-cultural society, is topical and development is achieved in another way - by group cooperative learning. Many programs are based on a certain technique - "making up a jigsaw-puzzle". This name resulted from similarity of the method with the respective game (Aronson, 1998).

Cooperative groups are represented by small groups of persons - trainees or employees. Within such groups, there is interdependency, determining the result of the general task accomplishment, and, consequently, the reward for final success. Thus, success is achieved due to the cooperative work of the whole team, the individual characteristics of certain individuals being insignificant. For example, at school, every participant in group gets a fragment of the "puzzle" inly, that is one person gets to know the history of a certain town, another one studies is geographic position, the third one examines its culture, etc. Consequently, to accomplish the task, the student has to be familiarized not only with his own task, but also get information from other group members; this way all the information given is restored. Thus, the puzzle is compiled.

This method has approved itself not in the USA only, but also in many European countries, as well as in Israel, Australia, etc. Appliance of this method contributes to:

- Increase of tolerance in the collective inter-ethnic relations;

- Development of friendly relations and comradeship within the inter-ethnic environment and among the representatives of different racial communities;

- Decrease in ethnical stereotypes significance, the gravity center being transferred to individual differences versus the group peculiarities;

- General identity restoring;

- Increase in self-appraisal, reduction of anxiety and development of the collective general self-discipline, including the representatives of either cultural or ethnic minorities.

The social development present-day reality takes a more clearly defined form of poly-cultural area, which is based on multiple intercepts of various theoretical and practical dialogues. As a result, there is a necessity of a correct interpretation of the "pluralistic paradigm" factor, resulting from a clearly defined recognition of the social and cultural existence plurality, differences and richness, as well as of the citizen's freedom and rights, religious tolerance, nonviolence and necessity of an intercultural dialogue initialization.

Regarding the society through the prism of the "pluralistic paradigm" factor creates the possibility for a theoretical understanding of new dimensions and profiles (poly-cultural, multi-cultural, and trans-cultural), within which a new 
educational policy should be set up with a view to organize and define certain admissible individual behavior patterns within a poly-cultural society.

Referring to the poly-cultural society, various theoretical and political disputes of the contemporary development are held (communicative, multicultural, post-colonial, and post-modern). These disputes refer to the real multi-culturalism policy, based on its own educational specificity. In this context, there is a significant positive factor reflected in the recognition of significance and value of the most fierce disputesdifferences on their direct adoption and sustenance, as well as of the reproduction and duplication at all personality development levels.

\section{Discussion}

At present, the "differences" ideology itself is characterized by an important social and political context. This is shown in the liberalism logic with regard to a politically correct recognition and "evolvement" of different cultural values and a "system" regulation of these peculiarities. Conservatives emphasize the importance of "non-system" society and promote the concept of the "natural diversity" versus the politically defended "difference". The liberal-type individual behavior patterns within a poly-cultural society take the form of the "universe of differences", which is more and more often subject to critical comments from different parts, including representatives of the postmodernism trend. Thus, J. Bodrijar stated that the universe of difference comes to a standstill in the course of its development, as the notion tandem is a deadlock itself. The difference specification resulted in the emergence of such trends as racism, as an indicator of the inexorable unreasonable difference. Also, according to Bodrijar many cultures did not ever set the goal of development in terms of either differences or universalism. This process has continued until the Russian media has put an accent on the importance of poly-cultural society existence in the context of multi-culturalism and tolerance, these 2 trends being the main professional behavior guiding factors, taking into account its diversity, pre-eminence, as well as its values and practices invincibility.

The notion of poly-cultural society intercrossed with the terms "multi-cultural society" and "multi-culturalism" starting from the 60s of the XXth century, when these notions have been adopted for an organized development of persons' behavior within multi-segment societies - multi-religious, multi-racial, multi-ethnic, multinational, etc. The term multiculturalism has been adopted 1971 and it was perceived at the phenomenon level due to recognition of the assimilating efforts inefficiency, these efforts being made by many states. Consequently, an ideal model of the society integration was set up starting from the 70s. The research showed: to make the variety subject to a general liberalism theory pattern it is necessary to apply a conservative way of thinking or, at least, a mentality based on explanations resulting from a nonlinear reasoning and historical dynamics (the works of J.Schumpeter may be suggested).

The difference between the notions of "multi-cultural society" and "poly-cultural society" is reflected in the "nonconsistency" and lack of "linearity" between views on the multitude of social elements and the distance of the latter from "modality" extensively imposed and promoted. Consequently, the "poly-cultural society" development peculiarities allowed a more detailed description of the modern social environment resulting in efficient behavior norms setting up. In this case, it is possible to work out or adopt the corresponding theoretical and political disputes, implement certain communitarianism and multi-culturalism policies, etc.

Despite multiple researches in the poly-cultural society area, according to many investigators' opinions, including the opinion of C.Leontiev, the notion of poly-culturalismas an "unaveraged" diversity is a "blooming complexity". In this case, how can certain specific patterns and norms of individual behavior be examined?

From the semantics viewpoint, the notion "poly-" (meaning plurality and manifoldness) is applied with reference to poly-cultural society, with an emphasis on the society area limits initially based on poly-cultural differences diversity, on the one hand, and the cultural differences differentiation and diversification processes, on the other hand, these processes contributing to the poly-cultural area consolidation. In the last case, the "pressure" and "compression" effect has an important disadvantage - temporary existence, that is a limited poly-culturalism continuum. For this reason, behavior patterns should be developed in the framework of stability, and namely steadiness (especially when speaking about the poly-culturalism area), as well as communication enhancement (temporary and dynamic relations, migration, connections among subjects of various poly-cultural areas).

Evolvement of behavior patterns in a poly-cultural society directly depends on its stability. To achieve stability, it is necessary to settle the issues of its area organization and safety, this area requiring order, security, life guarantees, and respect for human rights. Most development issues refer to analysis of institutions defining the concrete development vector, as well as a series of educational and political initiatives and decisions providing the social and cultural policy of poly-cultural environment evolvement. Stability of the poly-cultural society itself is defined by the efforts of cultural and educational institutions, organizations, mass media, etc. 
The communication issue within the poly-cultural society is reflected in mutual- and inter-relations, contacts of different neighboring cultures' bearers, and their awareness of "cultural differences" importance. The most important factors influencing communication are mass media, of which the influence is in progress, and stereotypes cultivating mass cultural necessities and averaging differences between cultures. Dynamics of modern poly-cultural society representatives interaction leads, more and more often, to overcoming the neighboring states' boundaries and penetration into other socially stable territories, mono-worlds. The lack of respect and tolerance to culture and values of other society representatives may cause conflicts and these societies' reciprocal devastation.

Communication within a poly-cultural society is a result of contact and mobility of different cultures' subjects on both positive and negative sides. Thus, for example, network mobility became an impulse for the development of communication among different persons within a poly-cultural society. This resulted from the fact that "mobile operators" are a group of intellectuals with a high-paying job, own business, and access to network. Besides, rich and literate people often adopt the "funk tribe" ideology, expressing their refusal from any ideologies, former kindred and ethnic relationship, offering new opportunities to future "post-capitalistic world" holders. Nevertheless, as reality shows, migration, mobility, meetings with other cultures become development and emancipation factors.

Communication (various behavior patterns) and stability (irrespectively of external factors) are interconnected, but also contradictory phenomena within a poly-cultural society. Network multi-media technologies offer to subjects the opportunity to reach the virtual dimension level, creating public areas in the Network, thus setting up diasporic environments at the national level, transferring the analysis of the individual behavior patterns within a poly-cultural society to the developing epistemological level of a certain transculture. Nevertheless, as new technologies develop, other "cultural differences" subjects express insufficiency of a usual, earth stability, and not the virtual one; this insufficiency makes it difficult for them to settle their life world in the context of a complex poly-cultural environment.

The investigations made showed that as a result of the implementation of new programs on improvement of conditions for communication among subjects of the poly-cultural society, the system entropy decreased and a new sensible energy impulse was experienced by many European countries. Trans-territoriality (development of new habitats, geographic places, new territories, increase in the amount of geographic information), intermarriages (new communication and genofond), trans-civility (tendency to learn new languages, symbols of other cultures, behavior patterns, etc.) are the result of a positive coexistence of the poly-cultural society.

Referring to the education issue, there should be mentioned that to educate the new generation - basis of the polycultural society future - every student from the EU spends one year outside his country, during the education process. Evaluating prospects, there may be noted that such mobility will result in tens of thousands of mixed marriages at minimum, this leading to a complete change of the EU elite image. In conclusion, improvement of the individual modern communication patterns within a poly-cultural society by enhancing its stability results in the implementation by Europe of a new poly-cultural project referring to "trans-influence" and unification of the Old World territory citizens.

However, it is often that the ideas of poly- and multi-culturalism do not evolve, but simply transplant in the course of the leading authorities' liberal trend promotion. This leads to destabilization in society at all its levels and puts the basis for the shift to "frontier" and "placelessness", enhancing the community undesirable split, excluding the efficiency of the "national project" and the main goals, of which the setting up depends on the poly-cultural society. For this reason, politicians and theorists hold endless disputes on the efficiency of multi-culturalism, as the main policy of the poly-cultural society "national project". They put an accent on the disregard by subjects of the poly-culturalism as it is and the often "inurement" of this trend, this resulting in a disbalance of the existent heterogeneity of the social environment.

\section{Summary \& Conclusions}

It is needles to speak on the relevance of research in the poly-cultural society area (trans-civility, multi-culturalism) for Russia, taking into account its racial, religious, ethnic specificity and multiplicity, as well as the increasing ethnic and cultural mobility and confrontations. Nevertheless, special attention should be given to the specific character of multiculturalism on the basis of Russian poly-culturalism, as a certain phenomenon analyzed in terms of its inconsistency and variety.

At present, it is difficult to emphasize a certain multi-culturalism pattern in the context of Russian projects on a stable poly-cultural society organization. There are no outstanding "sustainable" Western innovations, such as tolerance to guests, political correctness to gays, etc. Reality shows that the Russian society barely adapts to radical changes and the inefficiency of poly-culturalism improvement models is obvious. At the same time, this would be a stress-factor, inciting instability and doubts within the society on the correctness of the authorities' decision-making. The result of such measures is comparable to the trans-cultural crossing issue settlement, on the basis of the cosmopolitan disputes held by 
the political elite.

The relevance of multi-culturalism and poly-culturalism trends for Russia is obvious. Going into details, there should be mentioned that the notions themselves should not be rigidly opposed despite the difference in their principles. Obviously, the multi-culturalism policy is not the basis for poly-cultural society organization (modern Russia is an example), and the multi-culturalism policy may perform its functions to the utmost despite the real necessities and interests of the poly-cultural society. There should be mentioned that a complex of separate and independent factors represent one of the conditions for poly-cultural society stability. These factors are: national security, educational environment, state policy, legal framework corresponding to the existent interests, multi-culturalism policy appliance. Combination of each of these elements increases the success of different cultures and ethnic communities' coexistence, and certain communication norms and patterns setting up.

Why does the low efficiency of multi-cultural and trans-cultural projects adherent to the Russian poly-cultural reality become more obvious with the course of time? Organization of the corresponding conditions for the individual communication within a poly-cultural society takes place in the course of social and cultural changes, but, in most cases, the attempts to take measures lead to conflicts and separation. Many territorial units caused the appearance of largescale, practically uncontrolled phenomena - immigration-migration-emigration, urbanization, movements, etc. "Innovations" and a wrong approach to the organization of a stable poly-cultural society created a conditional "marginality" atmosphere, characterized by diffuse, intermediate interface of cultural existence. The communication, cooperation, and cultural interaction patterns within the modern poly-cultural society became hybrid and meditative. The problem settlement becomes more difficult due to the personality self-identification issue at the social, psychological, virtual and territorial levels. This process reflects slowly, coming to the knowledge of social practice and national science. There began processes and phenomena in the country. These processes and phenomena require measure-taking by the large spectrum of educational and fostering institutions.

Organization of individual interaction and communication within the national poly-cultural society requires the implementation of tested programs implemented by Western specialists, but also the setting up of our own multi- and poly-culturalism models, aimed at settling problems at all levels and in all directions. It is necessary to perform a detailed research of cultural and ethnic integration, as well as of the possibility to hold a permanent dialogue with the subjects and communities of other cultures. Another important trend in communication patterns and behavior norms setting up is improvement of the educational system in modern Russia.

\section{Acknowledgements}

The research was performed due to a detailed examination of works and reports made by the leading specialists in the area of the poly-cultural society basis setting up, namely: Goncharova Svetlana Vladimirovna (Ph.D. in sociology, report "Modern Education: Human Potential or Functional Literacy"), ProtoireyRostislav (Moroz) (leader of the religious unit, catechesis of the Vladivostok eparchy, report "The Issue of the National Identity Evolvement in Modern Russia"), AvilovGhennadiyMihailovich (research of the international scientific conference proceedings "Nalchik-2001", "Tolerance and Poly-Cultural Society"). Also, the experience and conclusions of scientific research workers from Europe, USA and countries of the Near East have been examined.

\section{References}

BogdanovaA.I. Role of the Educational Environment in the Modern Poly-Cultural Society. Siberian Federal University, Krasnoyarsk city, Russia.

BorisovA.A. AmericanConservatives and Multi-Culturalism: autoabstract, Ph.D. in history, Perm, 2000.

Vasyutenkoval. V. Individual Social Health within a Poly-Cultural Educational Environment, 2008.

DeryabinaS.R. Russia and the Experience of Multi-Culturalism: pro and contra // Ethnic View. 2005. No. 1-2. P. 15.

Malikovskayal.A. Globalization and Trans-Cultural Challenge.

Malikovskayal.A.Problems of Education in a Poly-Cultural Society. Проблемыобразованиявполикультурномобществе. Cit: Russian Federation Federal Education Agency. URL: ifl.uspu.ru/.../cathedra english/tezis2009.doc (date: 11.03.2010).

Proceedings of the international scientific conference as part of the Liberal Arts Festival "Nalchik-2001", September, 3-6, 2001. "Tolerance and Poly-Cultural Society".

MokinK.S. Strategies of Ethnic Migration Communities Adaptation in the Poly-Cultural Environment// Saratov, 2007.

OsipovaN.V. Reasons of Conflicts in the Poly-Cultural Environment // Tula State Teacher's University n.a. L.N.Tolstoi.

Fedorenkol. V. Organization of the Ethical and Legal Consciousness of Students within a Poly-Cultural Environment// SCADT 13.00.08. 